BOOK REVIEW

\section{Pediatric and}

Adolescent Gynecology: Evidence-Based Clinical Practice (2nd revised and extended edition)

Charles Sultan (ed.). Basel, Switzerland; Karger. 2012. ISBN-13: 978-3-805-59336-6. Price: f140.73. Pages: 396 (hardback)

This is a most interesting book. It is a collection of chapters each of which stands independently. The editor is to be congratulated for the fact that there is little overlap or contradiction between individual chapters.

The book is divided into three sections: Background and Tools, The Prepubertal Girl and the Adolescent Girl. There are four chapters in the Background and Tools section that describe examination, normal pubertal development, endocrine evaluation and diagnostic methods. The Prepubertal Girl section has five chapters that as well as considering disorders of sex development also include a chapter on sex abuse. The third section, on the Adolescent Girl, comprises well over half of the book and has 15 chapters with topics ranging from delayed puberty to culturally sensitive adolescent care. I think the chapters on adolescent contraception, teenage pregnancy and high-risk sexual behaviours would be of most interest to those working in our field.

The authors are from Europe, the Middle East and the USA. There are none from the UK. So although UK practice and Faculty guidelines are mentioned, much of the clinical practice differs. In the management of heavy dysfunctional uterine bleeding, high-dose progestogens and the intrauterine system are said to have little role and the text suggests that girls with a haemoglobin level of $<10 \mathrm{~g} / \mathrm{l}$ should be hospitalised. The chapter on contraception appears to suggest that if a girl has a condition considered UKMEC 2 for the combined pill she should take the progestogen-only pill.

Despite these inconsistences between UK and European practice this is an interesting and informative book. I particularly enjoyed the chapter on precocious puberty that discusses the wide range of presentations and racial differences.

Most of us working in sexual and reproductive healthcare will not refer to a book such as this on a daily basis but it is very useful to have this on the shelf for reference when a child or adolescent attends.

Reviewed by Gillian Robinson

Associate Specialist, Reproductive and Sexual Medicine, Guy's and St Thomas' Community Directorate, London, UK; Gillian.Robinson@gstt.nhs.uk

J Fam Plann Reprod Health Care 2014;40:147. doi:10.1136/fprhc-2014-100900 